\title{
Interpretation of Drill Stem Test
}

Sarah N. S. All-Said Noor ; Dr. Mohammed S. Al-Jawad**; Dr. Abdul Aali AlDabaj $^{* * *}$

*Exploration petroleum company, ${ }^{* *}$ University of Technology, *** Ministry of Oil

\section{$\underline{\text { Abstract }}$}

The behavior of pressure derivative analysis and pressure build-up analysis expressed and discussed in this paper. Data from the drill-stem test report for field example through closing the vertical well (Build-up period) analyzed using the ECRIN KAPPA software. Build-up analysis used to estimate characterizations of reservoir: permeability, initial pressure and skin factor. Pressure derivative analysis used to know the type of flow regime, reservoir boundaries, wellbore storage and other parameters. IPR compared with the Vogel method by calculating the constants $\left(0.084755,1.4428 * 10^{-3}\right.$, and $\left.-8.5207 * 10^{-7}\right)$ to replace Vogel's equation constants $(1.8,0.2$ and 0.8$)$. Abnormal point is located in a single phase region. Its pressure is greater than that of the next point but its production rate is lower than that of the next point. Productivity index calculated depending on the last production rate. Good results are obtained of determination formation properties by using drill-stem test data instead of production test data. Formation damage is recognized from buildup analysis and constant wellbore storage, unit slope and radial flow regime are recognized from pressure derivative analysis.

\section{Introduction}

Tests on oil and gas wells are performed at various stages of drilling, completion and production [1]. During a well test, the response of a reservoir to changing production or injection conditions is monitored. Since the response is, to a greater or lesser degree, characteristic of the properties of the reservoir, it is possible in 


\section{NO.10 Journal of Petroleum Research \& Studies ( JPR \& S)}

many cases to infer reservoir properties from the response [2]. The productive capacity of a reservoir can be determined by using the information obtained from flow and pressure transient tests about in situ reservoir conditions. Pressure data are the most important in reservoir engineering. Directly or indirectly, they enter into all phases of reservoir engineering calculations. Therefore, accurate determination of reservoir parameters is very important. In general, oil well test analysis is conducted to meet the following objectives [3]:

1. To estimate well conditions and reservoir characterizations.

2. To obtain reservoir parameters for reservoir description.

3. To determine drilled length of oil well and the producing zone.

4. Estimating skin factor and completion-related damage to an oil well.

Inflow performance relationship (IPR) also estimated in this paper is illustrated graphically by plotting bottom-hole flowing pressure $\left(\mathrm{p}_{\mathrm{wf}}\right)$ vs. production rate $(\mathrm{q})$ on a Cartesian plot. It is straight line for $\left(\mathrm{p}_{\mathrm{wf}}\right)$ greater than bubble point pressure $\left(\mathrm{p}_{\mathrm{b}}\right)$ when productivity index ( $\mathrm{j}$ or PI) is a constant, but when productivity index is changing the slope of IPR is changing too at $\mathrm{p}_{\mathrm{wf}}<\mathrm{p}_{\mathrm{b}}$. Gasbarri et al (2009) created a general Vogel type correlation effective for light oil reservoirs and heavy oil. Jahanbani et al (2009) [5] presented a general method to predict IPR curve of oil wells at $\left(\mathrm{p}_{\mathrm{wf}}<\mathrm{p}_{\mathrm{b}}\right)$.

ECRIN KAPPA software is used to interpret well test analysis and calculate petrophysical properties. Its methodology is based on the use of the pressure derivative. This paper discussed pressure derivative. In the 80's Bourdet [6] and others introduced the derivative concept which helped to make type curve matching more easy than the previous one, and sometimes also without the need of the matching procedure. The application of the pressure derivative plot is that it is able to display in a single graph many separate characteristics that would otherwise 


\section{NO.10 Journal of Petroleum Research \& Studies ( JPR \& S)}

require different plots such as [finite conductivity fracture, infinite conductivity fracture dual porosity behavior, closed outer boundary, linear impermeable boundary and constant pressure boundary [6]. This paper will explain how analysis of well test data can be achieved by using Inflow performance relationship (IPR) plot, Buildup plot and pressure derivative plot.

\section{Drill- Stem test analysis}

Drill-stem test analysis is a recorded of bottom hole flowing pressure $\left(\mathrm{p}_{\mathrm{wf}}\right)$ when the well is opened to production and well build up pressure after $\operatorname{shut-in}\left(\mathrm{p}_{\mathrm{ws}}\right)$. Drillstem testing provides a method of temporarily completing a well to determine the productive characteristics of a specific zone. The analysis of pressure data in a properly planned and executed DST can provide, at a sensible cost, good data to help estimate the productivity of the zone, the completion practices, the extent of formation damage and perhaps the need for stimulation. A drill-stem test provides an evaluate formation properties and wellbore damage [3].

There is however two main categories of drill stem tests [1]:

\section{Open Hole Drill-Stem Testing}

If hydrocarbons are detected in either cores or cuttings during drilling or indicated by the logs, an open hole DST provides a rapid, economical means to quickly assess the production potential of the formation. However the technique requires the hole to be in very good condition and highly consolidated as the packer elements actually seal on the rock face. Open hole drill-stem tests gather important early information, but reservoir testing requires more data over a longer period. The extent of reservoir investigated increases with test duration. A key factor governing the duration of an open hole test is wellbore stability. At some point the well may cave in on top of the packer and the string may get permanently 


\section{NO.10 Journal of Petroleum Research \& Studies ( JPR \& S)}

stuck down hole, calling for an expensive sidetrack. These hazards of wellbore stability have been eliminated by testing after the casing has been set and in many sectors particularly offshore, cased hole testing has replaced traditional open hole drill stem testing.

\section{Cased Hole Drill Stem Testing}

As offshore drilling increased, floating rigs became common, increasing the potential for vessel heave to accidentally cycle traditional weight set tools and even un-set the packer. In addition, deeper more deviated wells make reciprocal tools more difficult to operate and control and thus jeopardize the safety of the operation. A pressure controlled system was designed specifically for these applications, eliminating the need for pipe manipulation after the packer has been set, and eventually becoming the new standard in drill stem test operations. The type of DST for the example in this paper is well testing for Ahdeb Field [7].

\section{Pressure Buildup Test Analysis}

Horner's technique is used widely in well testing reservoir in petroleum industry [8].

Horner analysis is used to estimate reservoir properties (skin factor S, capacity kh and average reservoir pressure $\overline{\mathrm{P}}$ ) by using single and multiple well testing by application of several analysis techniques. Formation permeability can be estimated with slope of Horner (semi-log) plot. Shut -in the well after production, it is necessary of pressure buildup testing. The most common and simplest analysis technique requires the well to be produced at a constant rate prior to shut-in, either from start-up or long enough to establish a stabilized pressure distribution [9]. 


\section{NO.10 Journal of Petroleum Research \& Studies ( JPR \& S)}

Buildup test analysis is expressed by applied the principle of superposition for a well producing at rate $(\mathrm{q})$ until time $\left(\mathrm{t}_{\mathrm{p}}\right)$ then closed at rate $(\mathrm{q}=0)$ at $\Delta \mathrm{t}$ as shown in figure (1), important data for history plot as given in table(1) [7].

Table (1) Data for History plot

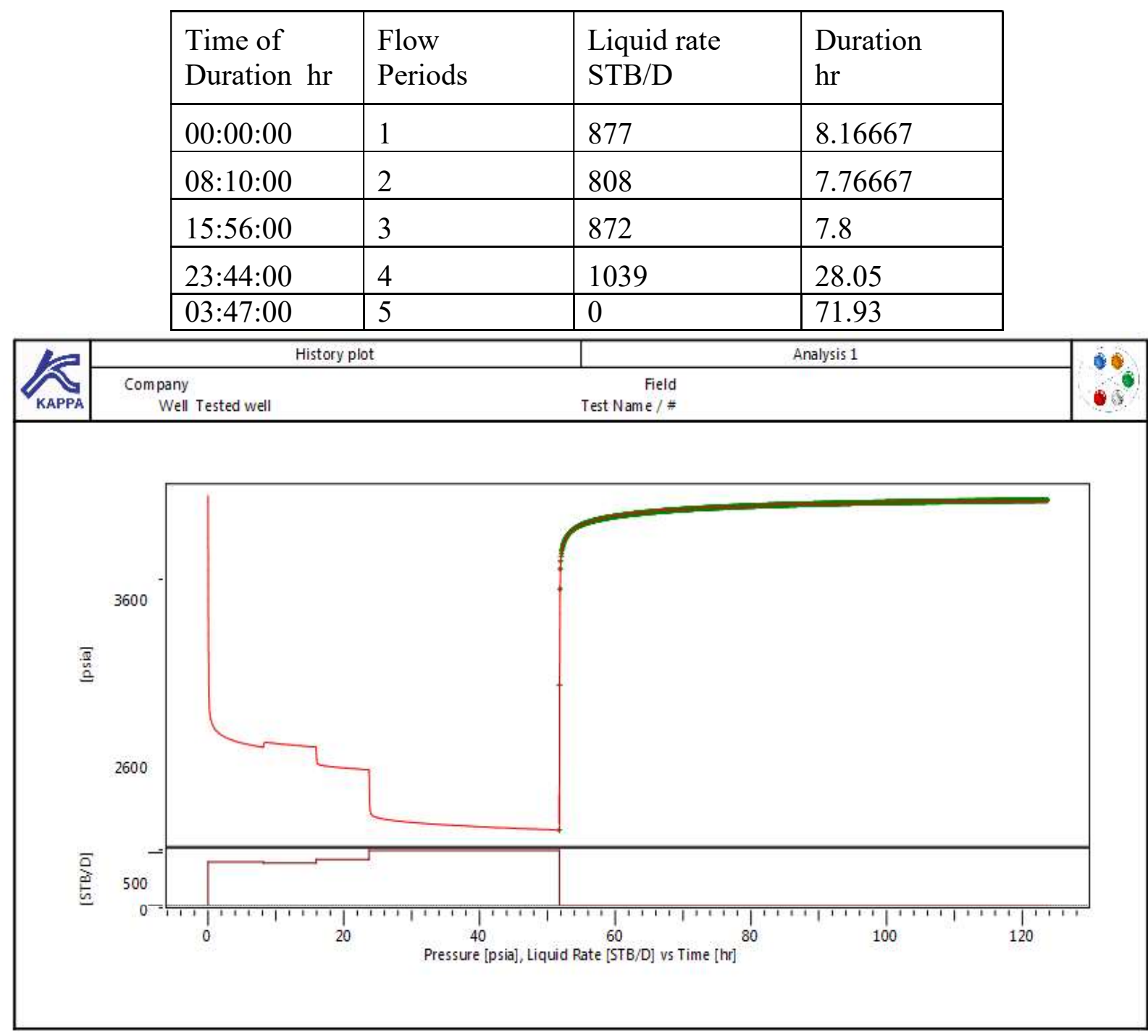

Fig. (1) History plot flow rate and static pressure vs. time 


\section{Horner Plot}

The straight line Horner plot contains all data. Capacity (kh) and skin factor (S) can be determined from data of straight line [10]. The single slope of Horner plot indicates the homogeneous reservoir, (semi-log) and Horner plots are shown in figure (2) and figure (3). Important data for Horner plot as given in table (2), the results of (semi-Log) and Horner plots are given in table (3).

Table (2) Input data for Horner plot

\begin{tabular}{|l|l|}
\hline Formation porosity, $(\varnothing \%)$ & 24.6 \\
\hline Well radius $\left(\mathrm{r}_{\mathrm{w}}\right), \mathrm{ft}$ & 0.400262 \\
\hline Formation thickness $(\mathrm{h}), \mathrm{ft}$ & 32.6444 \\
\hline Formation volume factor $\left(\mathrm{B}_{\mathrm{o}}\right), \mathrm{bbl} / \mathrm{STB}$ & 1.3027 \\
\hline Oil viscosity $\left(\mu_{\mathrm{o}}\right), \mathrm{cp}$ & 3.3806 \\
\hline Formation compressibility $(\mathrm{cf}), 1 / \mathrm{psi}$ & 3 \\
\hline Total compressibility $\left(\mathrm{c}_{\mathrm{t}}\right), 1 / \mathrm{psi}$ & 9.6435 \\
\hline Reservoir pressure $\left(\mathrm{p}^{*}\right), \mathrm{psia}$ & 4261.49 \\
\hline Bubble point pressure $\left(\mathrm{p}_{\mathrm{b}}\right), \mathrm{psia}$ & 2590.91 \\
\hline
\end{tabular}

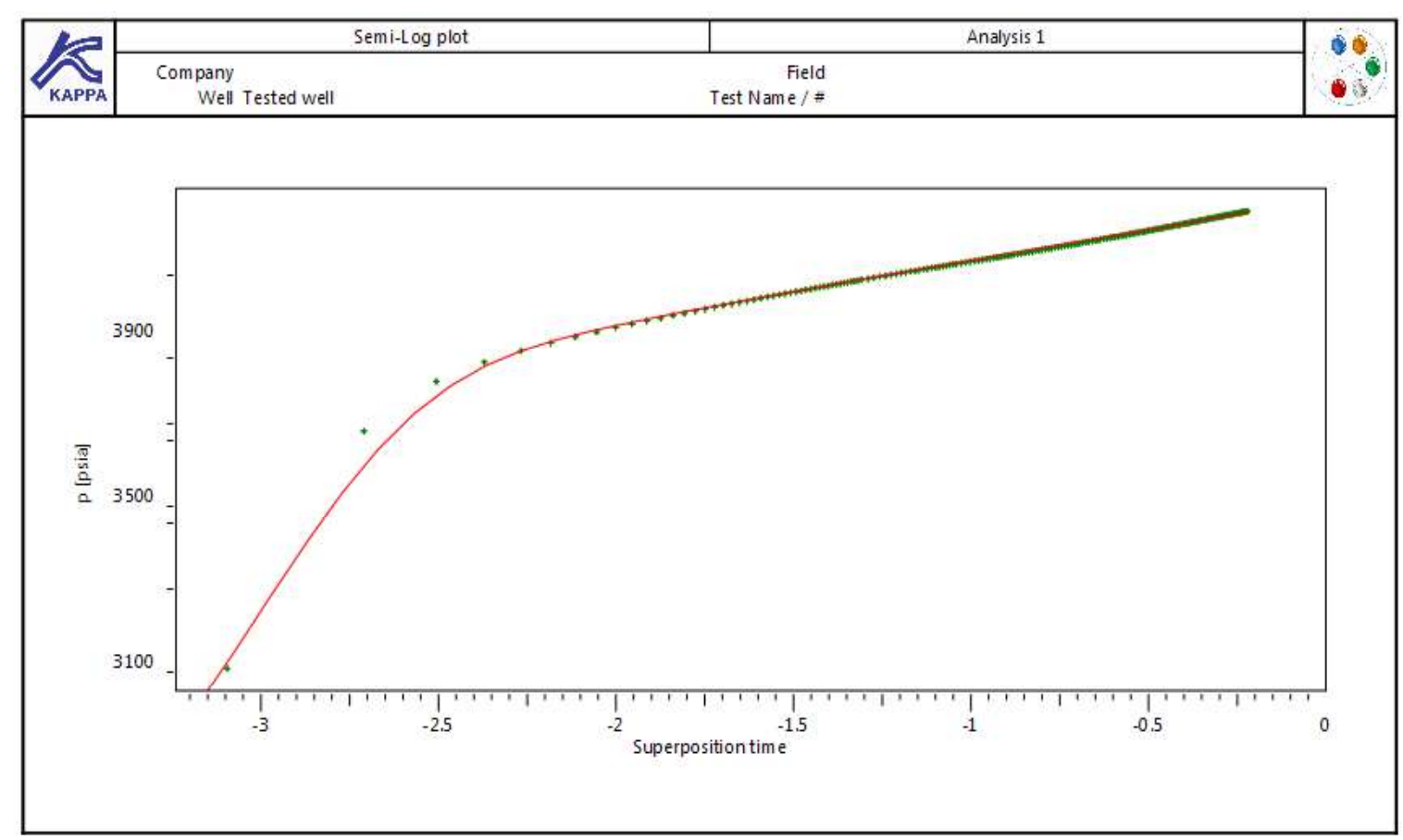

Fig. (2) Semi-log plot [static reservoir pressure (Pws) vs. Superposition time] 
NO.10 Journal of Petroleum Research \& Studies ( JPR \& S)

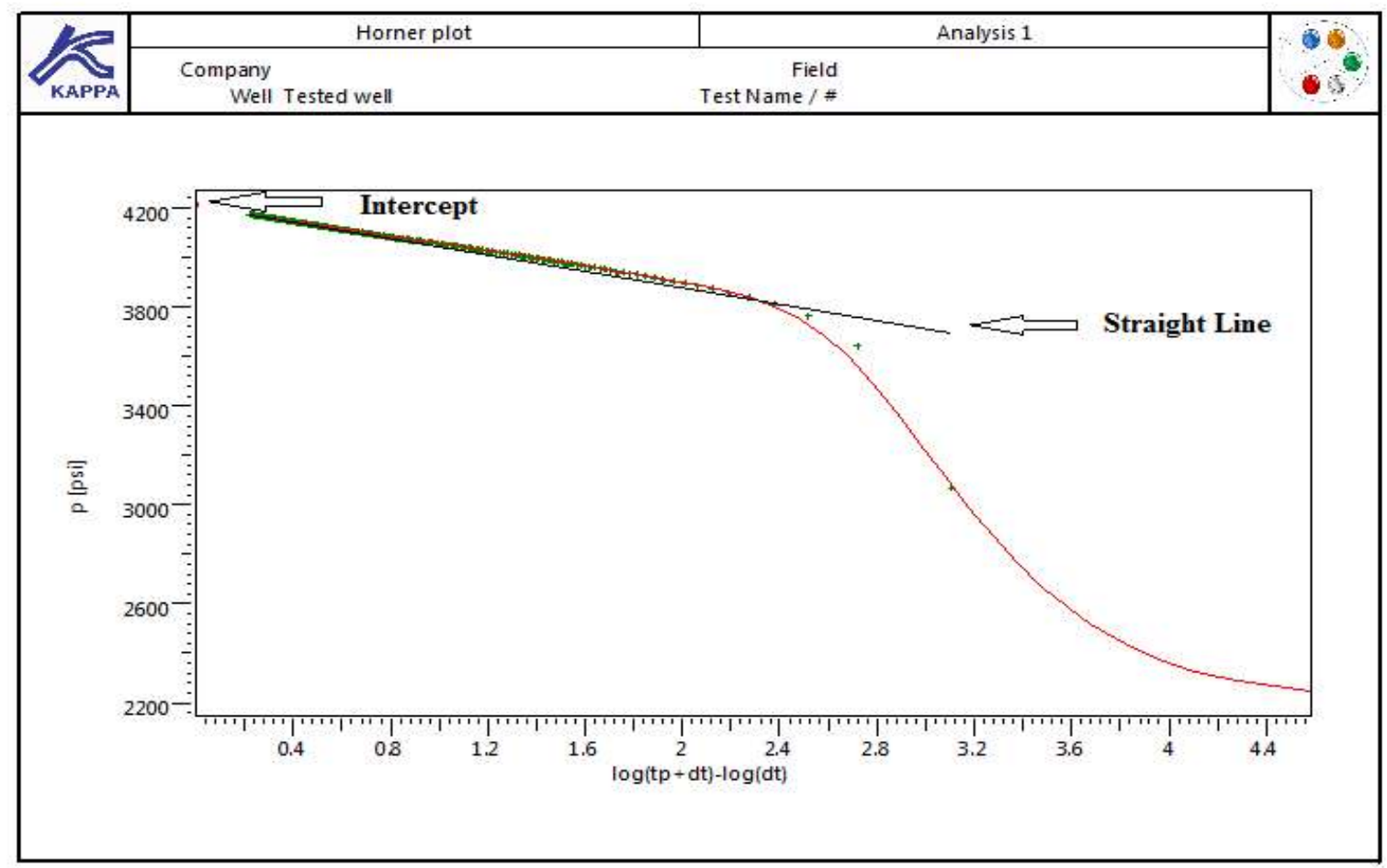

Fig. (3) Horner plot [static reservoir pressure (Pws) vs. Horner time]

The following equations are used to buildup analysis:

1- Horner time $=\log \left[\frac{t_{p}+\Delta t}{\Delta t}\right]$

$\Delta \mathrm{t}$ : shut-in time, hr

$\mathrm{t}_{\mathrm{p}}:$ Production time, $\mathrm{hr}$

2- Determined the slope of semi-Log straight line by eq. (2)

$\mathrm{m}=\frac{p_{w s 2}-p_{w s 1}}{\log _{2}-\log _{1}}$

3- Formation permeability can be estimated from Horner plot by application the eq. (3).

$\mathrm{k}=\frac{162.6 q B \mu}{m h}$ 
NO.10 Journal of Petroleum Research \& Studies ( JPR \& S)

4- Skin factor is calculating by eq. (4)

$\mathrm{S}=1.151\left[\left(\frac{p_{1 h r}-p_{i}}{m}\right)-\log \left(\frac{k}{\emptyset \cdot \mu \cdot c_{t} \cdot r_{w}^{2}}\right)+3.23\right]$

Table (3) Main results for Semi-log plot

\begin{tabular}{|l|l|}
\hline P Match, (psia) $^{-1}$ & 0.00793 \\
\hline Capacity k.h, (md.ft) & 5120 \\
\hline Permeability k, (md) & 157 \\
\hline Delta p skin & 1056.04 \\
\hline Initial pressure Pi, (psia) & 4203.3 \\
\hline Skin S & +8.4 \\
\hline Rinv. ,(ft) & 1080 \\
\hline $\mathrm{P}_{\text {avg }},(\mathrm{psia})$ & 4169.14 \\
\hline
\end{tabular}

\section{Inflow Performance Relationship (IPR)}

InFlow Performance Relationship (IPR) curve is the relationship between the flow rate of the well $(q)$ and the bottom hole flowing pressure $\left(p_{w f}\right)$ as shown in figure (4), important data for IPR curve as given in table (4).

Table (4) Input data for (IPR) curve

\begin{tabular}{|l|l|}
\hline $\begin{array}{l}\text { Oil production rate } \\
\text { STB/D }\end{array}$ & $\begin{array}{l}\text { Final flowing pressure } \\
\text { psia }\end{array}$ \\
\hline 827 & 3034.81 \\
\hline 808 & 2724.94 \\
\hline 872 & 2459.14 \\
\hline 1039 & 2200.51 \\
\hline
\end{tabular}


NO.10 Journal of Petroleum Research \& Studies ( JPR \& S)

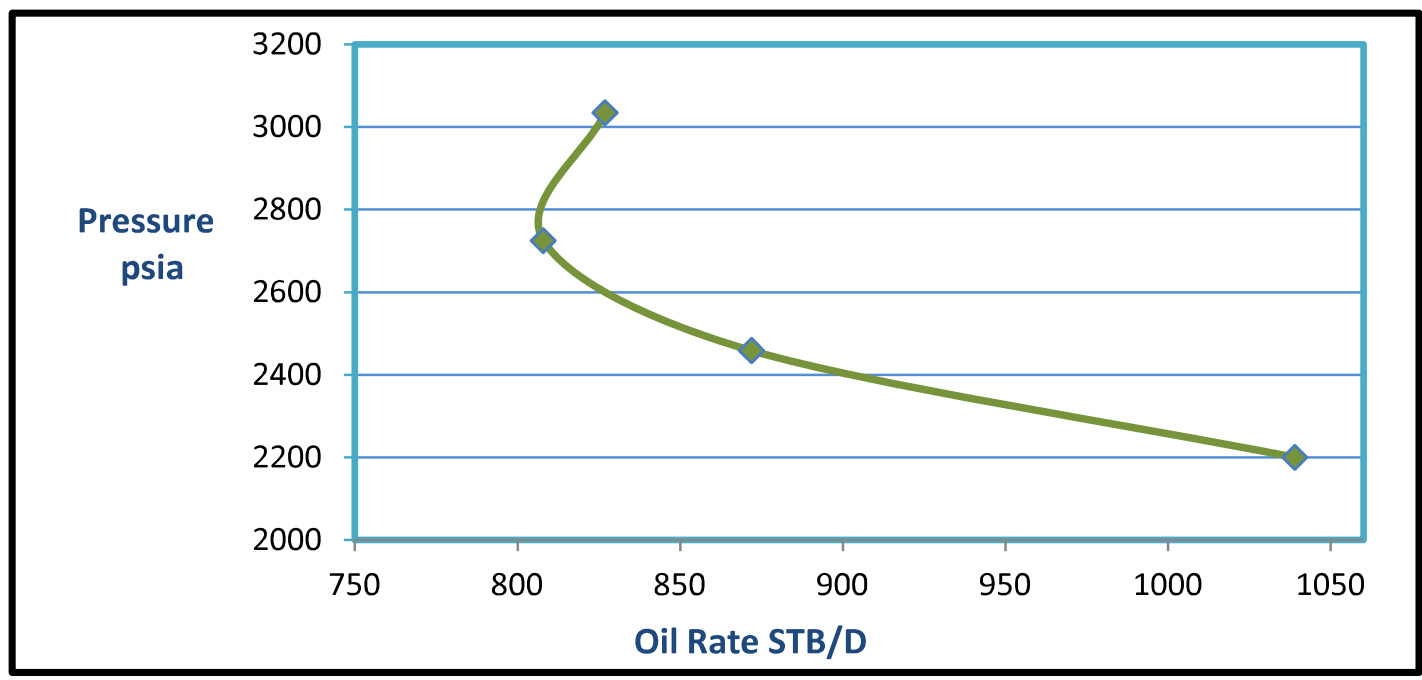

Fig. (4) In Flow Performance Relationship (IPR) curve for production data

Productivity Index $(\mathrm{PI})=\frac{\mathrm{q}_{\mathrm{o}}}{\mathrm{p}_{\mathrm{r}}-\mathrm{p}_{\mathrm{b}}+\frac{\mathrm{p}_{\mathrm{b}}}{1.8}\left[1-0.2\left[\frac{\mathrm{p}_{\mathrm{wf}}}{\mathrm{p}_{\mathrm{b}}}\right]-0.8\left[\frac{\mathrm{p}_{\mathrm{wf}}}{\mathrm{p}_{\mathrm{b}}}\right]^{2}\right]}$.

$\mathrm{PI}=\mathrm{j}=0.51061 \mathrm{STB} / \mathrm{D} / \mathrm{psia}$

$\mathrm{q}_{\mathrm{b}}=853.02 \mathrm{STB} / \mathrm{D}$

Matching between Vogel method and the equation from production data are shown in figure (5), eq. 6 \& eq.7.

$\mathrm{q}_{\mathrm{o}}=\mathrm{q}_{\mathrm{b}}+\frac{\mathrm{jp}_{\mathrm{b}}}{1.8}\left[1-0.2\left(\frac{\mathrm{p}_{\mathrm{wf}}}{\mathrm{p}_{\mathrm{b}}}\right)-0.8\left(\frac{\mathrm{p}_{\mathrm{wf}}}{\mathrm{p}_{\mathrm{b}}}\right)^{2}\right]$

$\mathrm{q}_{\mathrm{o}}=\mathrm{q}_{\mathrm{b}}+\frac{\mathrm{j}_{\mathrm{b}}}{0.084755}\left[1-1.4428 * 10^{-3}\left(\frac{\mathrm{p}_{\mathrm{wf}}}{\mathrm{p}_{\mathrm{b}}}\right)-\left(-8.5207 * 10^{-7}\right)\left(\frac{\mathrm{p}_{\mathrm{wf}}}{\mathrm{p}_{\mathrm{b}}}\right)^{2}\right]$ 
NO.10 Journal of Petroleum Research \& Studies ( JPR \& S)

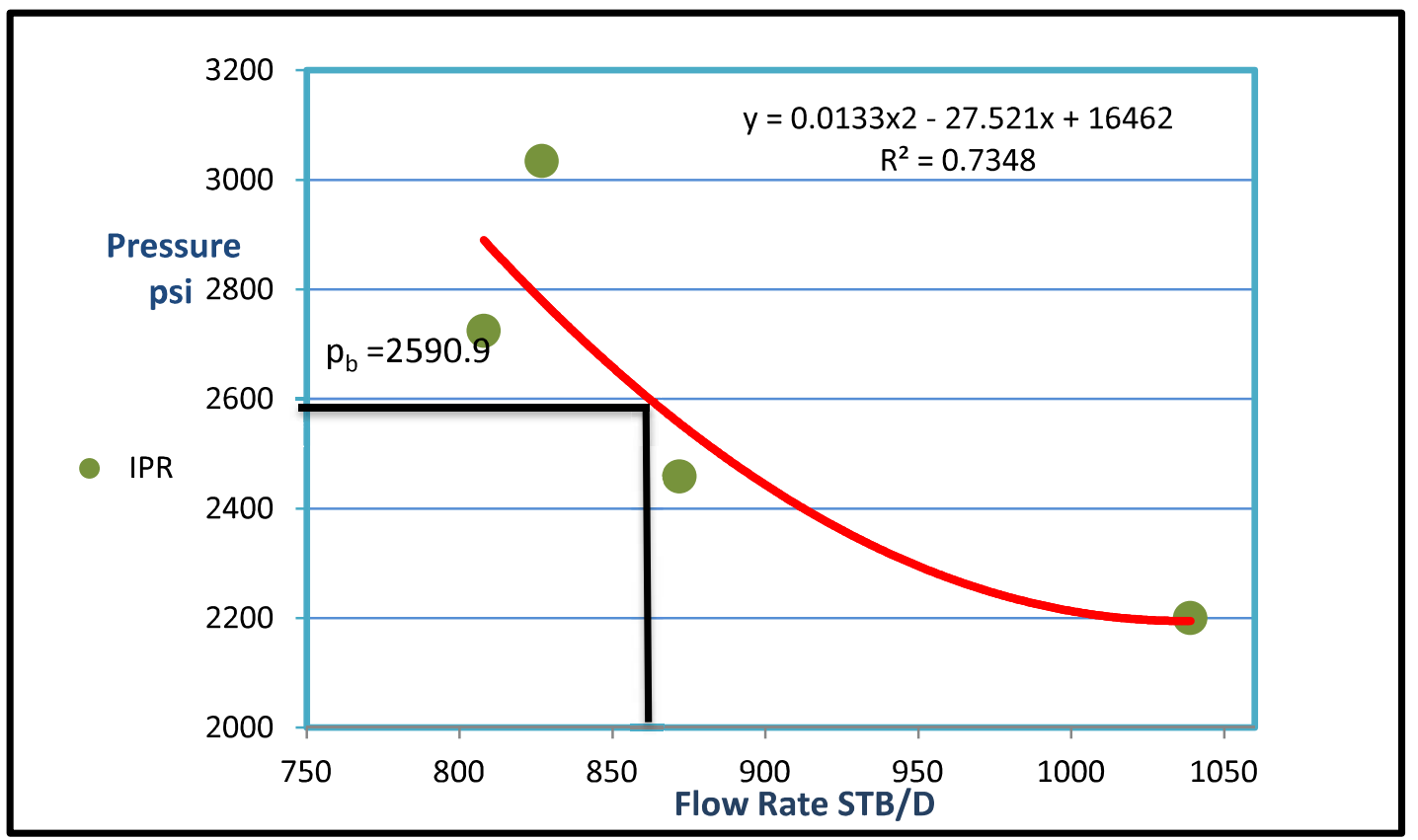

Fig. (5) Explained of matching between Vogel method and the equation from production data

The point of oil rate $827 \mathrm{STB} / \mathrm{D}$ at $3034.81 \mathrm{psi}$ in the inflow performance relationship plot is irregular point; it is located at pressure greater than bubble point pressure in a single phase region. The productivity index is lower in this zone.

\section{Pressure Derivative Log-Log Plot}

Pressure derivative analysis based on the observation the pressure variation that occurs during a well test is more significant than the pressure. Pressure derivative illustrated wellbore storage, region of reservoir near wellbore when the producer well closed and the flow continuing from the formation to the wellbore. Also, unit slope explained in pressure derivative analysis when the slope equal 0.5. Pressure derivative plot shown in figure (6). Main results of pressure derivative are given in table (5). 
Table (5) main result for pressure derivative analysis

\begin{tabular}{|l|l|}
\hline T Match, [hr $]^{-1}$ & 288 \\
\hline P Match, [psi] & 0.00793 \\
\hline C, bbl/psi & 0.00155 \\
\hline Total skin, S & +8.4 \\
\hline (K.h), total, md.ft & 5120 \\
\hline Rinv. ,ft & 1080 \\
\hline Test. Vol., bcf & 0.0293141 \\
\hline Delta P(Total Skin), psi & 1056.04 \\
\hline Delta P Ratio(Total skin), Fraction & 0.53574 \\
\hline
\end{tabular}

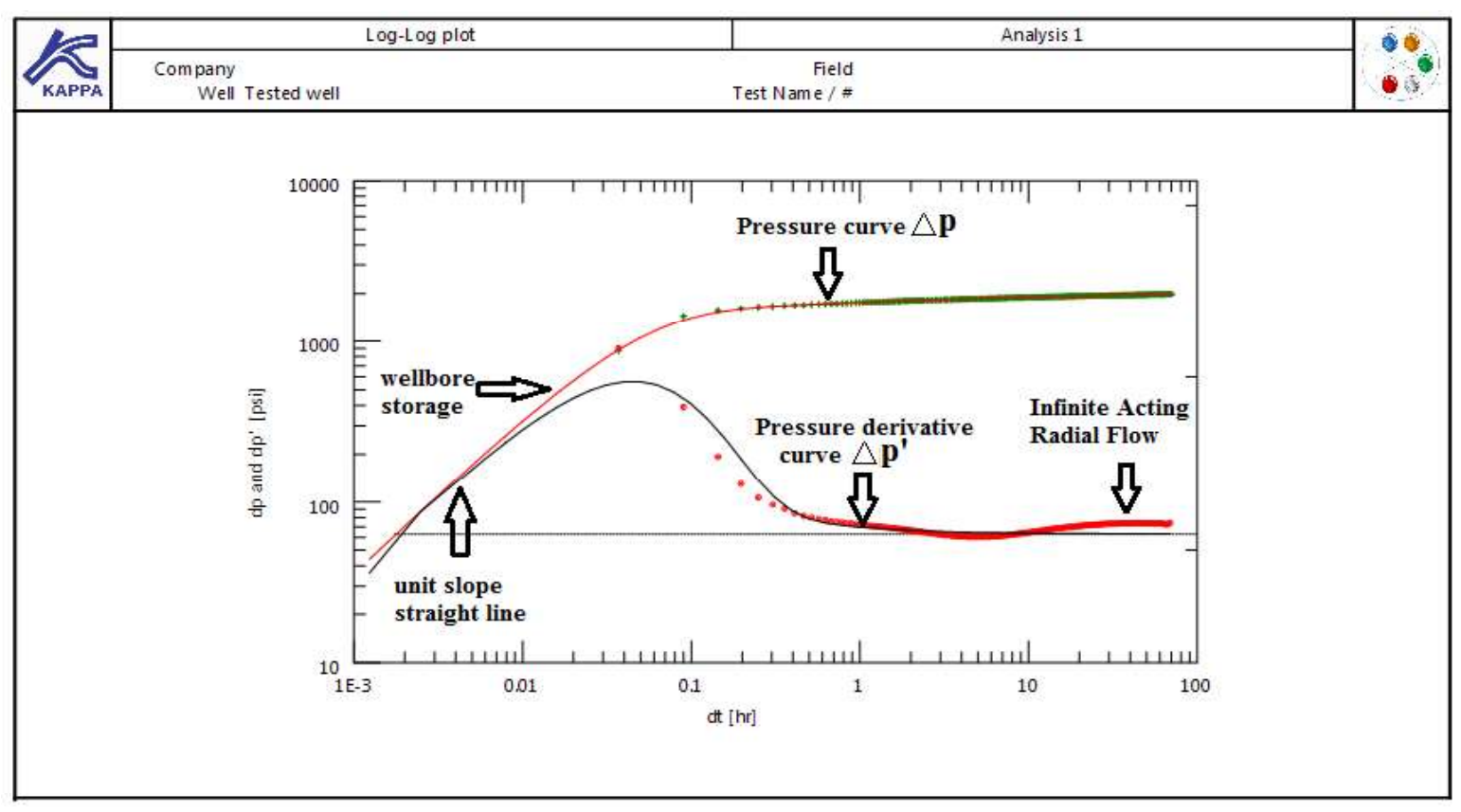

Fig. (6) Pressure and pressure derivative vs. time plot

Radial flow regime can be deduce by the flat region of the pressure derivative curve $\Delta \mathrm{p}^{\prime}$. Wellbore storage effect when the two curves, $\Delta \mathrm{p}$ and, $\Delta \mathrm{p}^{\prime}$, are beginning with the same slope.

The infinite acting radial flow is started after $1.5 \mathrm{log}$ cycles from the end of the wellbore storage effect, can be taken the linear portion for the determination (m) in the Horner plot [6]. When the $\Delta \mathrm{p}$ curve coincident with $\Delta \mathrm{p}^{\prime}$ curve in unit slope region, the wellbore storage can be considered as a constant [1]. 


\section{NO.10 Journal of Petroleum Research \& Studies ( JPR \& S)}

All data of buildup analysis (Horner plot) and pressure derivative type curve are used to estimate permeability; the values of permeability, from (Horner plot) and pressure derivative plot are identical and good values. Wellbore storage does not indicate a fractured reservoir.

\section{Conclusions}

1. Drill-stem test data is used to interpret pressure buildup test analysis and pressure derivative analysis.

2. Depending on the pressure derivative behavior, homogeneous reservoir, standard model with wellbore storage and skin effect, well model were selected to interpret the test data and calculate the formation parameters.

3. End wellbore storage region can be observed at the separation between pressure and pressure derivative curves.

4. The flat line is observed in derivative curve in the intermediate time that is indicated the radial flow regime.

5. The skin factor is calculated equal $(S=8.4)$ from $(\log -\log )$ plot that indicated the formation was damaged near well bore. 


\section{References}

1. Schlumberger; "Introduction to Well Testing", England, March 1998, Modern Reservoir Testing- Reference number SMP-7055-Schlumberger (1994).

2. Roland N. Horne, Palo Alto; "Modern well tests analysis", A ComputerAided Approach ,Stanford University, California, May (1990).

3. Amanat U. Chaudhry; "Oil Well Testing Handbook", Advanced TWPSOM Petroleum Systems, Inc. Houston, Texas AMSTERDAM, (2004).

4. Gasbarri S., Martinez V., Garcia J., Pinto R., Garcia L., and Gil C.; "Inflow Performance Relationships for Heavy Oil", SPE paper 122292 presented at the 2009 SPE Latin American and Caribbean Petroleum Engineering Conference held in Cartagena, Colombia, 31 May-3 June(2009).

5. Jahanbani A., Shadizadeh S.R.; "Determination of Inflow Performance Relationship (IPR) by well Testing", SPE paper 2009-086 presented at the 2009 SPE Canadian International Petroleum Conference held in Calgary, Alberta, 16-18 Jun (2009).

6. Bourdet D.; "Well test analysis - The use of advanced interpretation model", Handbook of Petroleum Exploration and Production, 3, (2002).

7. Well Testing Report for Ahdeb Field, (2009).

8. Horner D.R.; "Pressure Buildup in Wells", Proce. , Third world Pet. Cong., The Hague (1951).

9. Earlougher R.C.Jr.; "Advances in Well Test Analysis", Monograph NO.5 (1977).

10.Bourdet D. et al.; "A new set of type curves simplifies well test analysis" World Oil (May. 1983). 


\section{Nomenclature}

\section{English Symbols}

$\mathrm{B}_{\mathrm{o}} \quad$ Formation volume factor bbL/STB

$\mathrm{c}_{\mathrm{f}} \quad$ Formation compressibility $1 / \mathrm{psia}$

$\mathrm{c}_{\mathrm{t}} \quad$ Total compressibility $\quad 1 / \mathrm{psia}$

$\mathrm{h} \quad$ Formation thickness $\mathrm{ft}$

IPR Inflow performance relationship

$\mathrm{j}$ or PI productivity index $\quad \mathrm{STB} / \mathrm{D} / \mathrm{psia}$

k Permeability md

m slope psia/sycle

$\mathrm{p}_{\mathrm{b}} \quad$ bubble point pressure psia

$\mathrm{p}_{\mathrm{i}} \quad$ Initial pressure $\quad$ psia

$\mathrm{p}_{\mathrm{r}} \quad$ Reservoir pressure $\quad$ psia

$\mathrm{P}_{\mathrm{wf}} \quad$ Bottom hole flowing pressure

q Flow rate STB/D

$\mathrm{q}_{\mathrm{b}} \quad$ Flow rate at bubble point $\quad \mathrm{STB} / \mathrm{D}$

$\mathrm{R}_{\text {inv }} \quad$ Radius of investigation $\mathrm{ft}$

$\mathrm{r}_{\mathrm{w}}$ well radius $\mathrm{ft}$

s skin factor

$\mathrm{t}_{\mathrm{p}} \quad$ production time $\mathrm{hr}$

$\Delta \mathrm{t} \quad$ shut-in time $\mathrm{hr}$

\section{Greek Symbols}

$\Delta \quad$ Change, drop

$\varnothing$ Porosity \%

$\mu_{\mathrm{o}} \quad$ Oil viscosity $\quad$ c.p 